\title{
A Design Science Approach to Interactive Greenhouse Climate Control Using Lego Mindstorms for Sensor-Intensive Prototyping
}

\author{
Rasmus Ulslev Pedersen and Torkil Clemmensen \\ Dept. of IT Management, Copenhagen Business School, \\ Howitzvej 60, 2000 Frederiksberg, Denmark \\ \{rup.itm, tc.itm\}@cbs.dk
}

\begin{abstract}
In this paper, we describe a design science framework for the use of interactive, sensor-intensive prototypes to develop interactive greenhouse climate management systems. We emphasize the ways in which design science, and in particular what we call micro information systems, may enhance the human-computer interaction (HCI) aspects of emission control performance through better interactive control interfaces and the utilization of sensor network technology. By applying guidelines suggested in design science to the case studied, we identify a number of interactive prototypes that successively address core issues in this particular setting. Starting from a simple humancomputer interaction with a one-sensor-one-output prototype made in Lego Mindstorms NXT, we end up with a custom made sensor that addresses interaction with our particular user profile: the gardener. Thus, we provide a reference platform for combining micro information systems and human-computer interaction in design science research into environmental sustainability research.
\end{abstract}

Keywords: Sensor prototypes, design science, HCI, embedded systems.

\section{Introduction}

As the importance of eco-sustainable growth becomes increasingly important, the human-computer interaction and micro information systems research communities must address environmental sustainability challenges. In this paper, we describe a design science framework for the use of interactive, sensor-intensive prototypes to develop greenhouse climate management systems. Consequently, this study emphasizes ways in which applied design science can enhance indoor greenhouse climate management performance through the utilization of sensor network technology.

We identify the need for a design science framework for sensor-intensive systems and we provide a proposed reference platform for design science research into environmental sustainability using a series of greenhouse prototyping studies.

In order to contribute to the body of knowledge on environmentally sustainable HCI [22] and environmental informatics [1], we propose to combine HCI and microIS. This then forms a representation of a design space for green micro-IS system. 
This combination can then be used as a point of reference for further relevant work. The fundamental questions for design-science research are:

1. What utility does the new artifact provide?

2. What demonstrates that utility?

We use these questions for guidance in our research into interactive greenhouse climate management and control.

\section{Background}

This paper has been inspired by recent developments in design science research as described by Hevner, March, Park and Ram [3]. Design science research (DSR) is a model for evaluating novel artifacts. Therefore, it is different from other IS/HCI research methods that mainly direct attention toward observation. A DSR project creates - or generates - an artifact that is then assessed - or evaluated - with regard to its contribution to rigor and to relevance. In other words, the DSR artifact uses scholarly literature to form theories regarding the artifact that is created, and its ultimate test is the proposed relevance for use with practitioners.

In line with common DSR guidelines, we want to design rigorously. A part of this is to be able to reproduce prototypes and user-oriented evaluations of them. We propose to use what we call "throw-away" sensor-intensive, interactive prototypes. We suggest that reproducibility in sensor-intensive prototypes can be achieved by using re-buildable Lego NXT prototypes with instructions in terms of video clips showing how to build prototypes. In addition, we provide open source code of programs used to collect and display sensor input.

There are examples of DSR within neuroscience [2] and in sustainability research, such as Watson et al.'s environmental framework [1] using the design science guidelines provided by Hevner et al. in their seminal MIS Quarterly article, "Design Science in Information Systems Research" [3].

In HCI, DSR has been proposed to test the proposition that incorporating user modeling and usability modeling in software requirement specifications improves design [4], and more generally, HCI has been suggested as a design science discipline [5].

\subsection{Micro Information Systems}

The embedded and sensor context for this paper is greenhouse monitoring systems and management of same. Micro-IS research in this area also focuses on sensorintensive systems [6]. On an even wider scale, OECD [7] presents sensor technology as a fundamental enabler for addressing global challenges with regard to global warming.

We conducted this particular evaluation using a micro information systems design science framework [8-10] that shows how it is possible to incorporate micro-IS into existing frameworks. Our focus here is on rigorous design, as listed by the 5th Design Science guideline published by Hevner et al. Our artifact-driven approach in the creation 
of the micro-IS design framework, the reference platform, the generate/evaluate tool, and the demo application are captured by Guideline 1: Design as an artifact. The instantiation is a demonstration of the usefulness of the generate/evaluate method.

We recognize the importance of other disciplines; two such examples are decision support systems [11] and embedded networked systems [12]. Design science, as discussed in IS [13], guides the design of the artifact and the constructs, models, methods, and instantiations that sum up this meta-artifact.

At that point, the demands and needs for our prototypes are mostly related to size, form, and function for the designed artifacts. The design theory nexus is able to cope with multiple requirements [14]. It forms a method for adapting and extending the micro-IS framework. These constraints form the search space for an acceptable solution to the part of the real world business problem that the micro-IS is intended to solve. We created several prototypes, and for each evolution, we refined the next prototype on the basis of previous knowledge.

Eventually, an acceptable solution was reached by generating/building solution candidates and evaluating/testing them in the greenhouse information systems context. This approach ensures that future micro-IS projects are understood from an HCI and IS perspective rather than from a technical one. This micro-IS meta-artifact provides some function which is to be aligned with the requirements of the IS context. This forms the combined utility of the information system.

The micro-IS context might be best addressed with a more technology-focused design framework [3], and the HCI/IS context is best addressed with an action design framework [15].

\subsection{HCI in Interactive Climate Management}

In relation to design science, HCI has, for long, been conceived of by some researchers as a design science [16]. The iterative cycle of generate and evaluate designs of design science is at the core of HCI's user-centered design [4, 5]. However, the importance of combining embedded sensor-intensive systems with consideration of users' interactions with such systems has appeared more recently [17]. Within the climate control community (not in the HCI community), Van Straten et al. [18] proposed that the interactive use of sensor-intensive information about crop growth would allow greenhouse control strategies to become more optimal in an economic sense. Both long-term and short-term dynamics of the crop and greenhouse and external weather conditions could be considered in such interactive control strategies. However, a major challenge in the development of interactive control strategies is the lack of reliable crop development models for the wide variety of crops encountered in real settings and the consequential need for a sensible allocation of tasks for the human grower and automatic control systems. One proposed solution is a two-systems approach, an interactive sensor-intensive control system for day-to-day climate control, and another more decision- support-like system to consider the long-term effects of climate management on crop production [18]. Within such a grower-oriented framework, the grower interacts with the system by setting constraints on temperature, humidity, and other evapo-transpiration variables over a period of interest. 
The grower is supported by a model-based simulation system that predicts how these settings influence energy consumption, photosynthesis, and condensation [18].

In the HCI community, related work has been done by Pearce et al. [19, 20], who studied interactive gardening. They wanted to use what they called "everyday simulations" to allow non-specialists to experiment with and in an interactive way learn optimal strategies for watering gardens. In order to develop such a tool, they noticed "...the absence of design processes specifically tailored to this type of project..." [20], and suggested areas to consider in terms of developing a design process for such a tool. Among the identified challenges were how to allow HCI designers to develop a necessary level of understanding of the horticultural domain and in particular how to do this within a reasonable time period. The solutions included letting the domain specialists automate a large number of decisions and allowing the end-user to only gradually take part in the decision making as he or she becomes more knowledgeable. Secondly, the HCI designers tried to embody material constraints in the design, as suggested by work domain analysis [21]. In the end, they designed a software tool called SmartGardenWatering, which works as decision support for gardeners when defining watering schedules and use. In a study of 20 gardeners using the tool, the researchers identified issues of trust and confidence in the underlying horticultural models and their interactive use. They concluded that the outcome of the interaction with the software should not challenge "idiosyncrasies in existing practice" [19, p. $224]$ and that gardeners wanted models with higher granularity than those provided by the tested system.

More generally, the whole idea of designing interactive systems for sustainable environments and global climate management has been outlined by leading HCI researchers. Dourish [22] took the opportunity to explain how ICTs can be used to promote environmental sustainability on the part of IT users, but also warned that current HCI research is not sensitive enough in reference to the political and cultural contexts of environmental practice. The idea has also found support in the IS community, where researchers have proposed that information system design can be a catalyst for environmental sustainability as an expression of value-sensitive design [23]. Thus, the role of IS design in developing interactive systems for sustainable environment is being pressed in both IS and HCI communities. So far, most of this work has been on a grand scale of proposals, but the first steps toward meeting the new challenge in the creation of interactive systems, environmental sustainability, have been taken, e.g., [24]. However, rather than focusing on the grand global climate management challenges, in this paper, we report from the perspective of a micro-climate control (greenhouse and plants) research project [25].

\section{METHOD}

We introduced design science in the background section. From this window-accepted framework, we extracted the generate/evaluate activity [3]. The reason for doing so was the need for a clear way of combining the development of micro information systems and thus information systems with an embedded systems component, and the human computer interaction field. 
The separation of generate and evaluate activities is useful because it allows us to assume clear roles in each sequential prototyping effort. Moreover, we do not necessarily assume the same roles across all sequential prototyping efforts. In the very beginning, the HCI researcher may create throw-away prototypes using paper or clay. Later in the process, it could be that the HCI researcher is now in the evaluation role, while the other researcher generates electronic prototypes using Lego Mindstorms NXT. What separates these two activities is that each prototype is evaluated and the feedback is used in subsequent prototypes. The HCI evaluation activity covers both an activity where the HCI researcher is acting as an end user and, later, the HCI researcher will act as part of the design group which is sitting in the generate/evaluate new box.

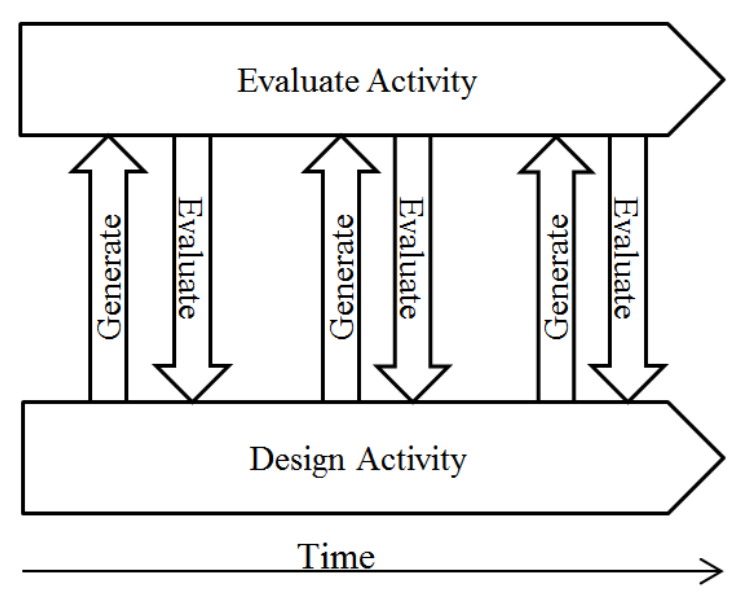

Fig. 1. Design activity and evaluate activity connected by generate and evaluate processes

In Figure 1, we describe how evaluate and generate activities are the two processes that connect the micro-IS and HCI activities. That is the subject of the following section. Each of the generate processes outputs a prototype which is then evaluated. This process is repeated, and the prototype is matured over time.

The process that we followed is this:

\section{GENERATE approach:}

1. Select a prototyping platform and design the new artifact: assemble, disassemble, construct, tear down, and work with the construction pieces while following through the steps below.

2. Refine the main IS problem and IS context and the information and control flows in the micro-IS system.

3. What are the basic phenomena to be monitored? To be controlled?

4. What set of sensors can monitor those phenomena?

5. What set of actuators is needed to regulate the physical entity? 


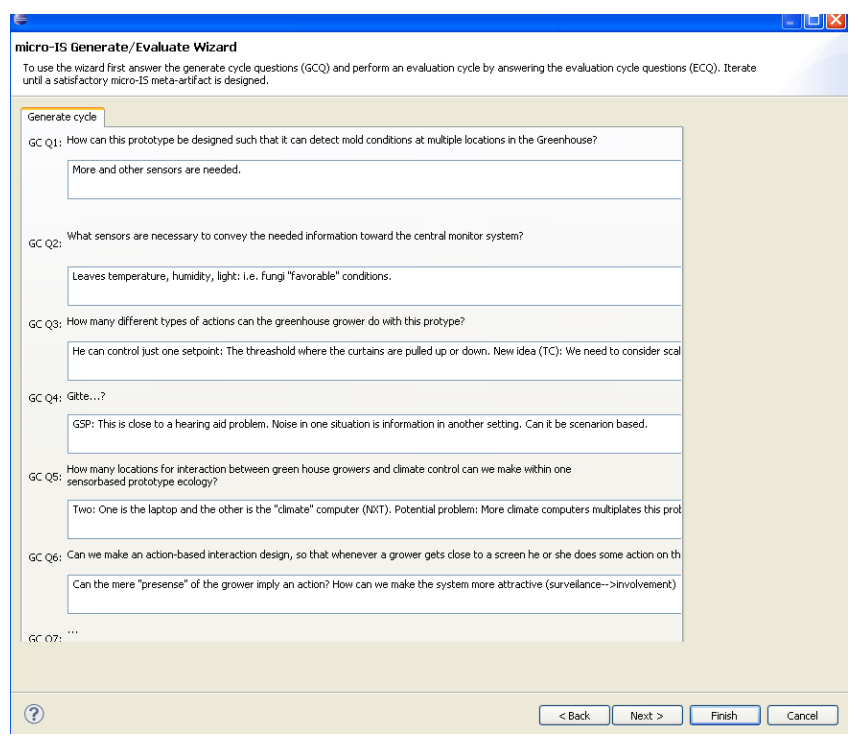

Fig. 2. Six questions from the Generate/Evaluate Wizard

We created a tool (see Figure 2) for capturing the generate/evaluate loop of our design process that had been developed in Java using the Eclipse environment. The tool asks the participants a number of questions related to the steps, which are outlined above.

Then the emphasis is switched to an evaluate loop, where a second set of questions is asked to capture how well the generated prototype worked (Figure 3). Besides these

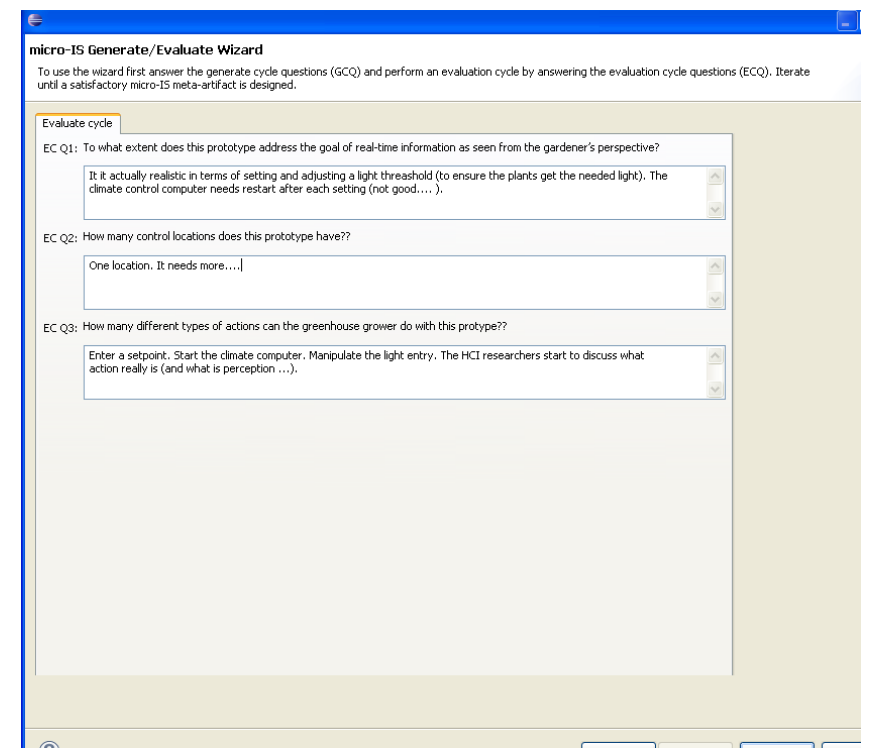

Fig. 3. Evaluate cycle from the Wizard 
evaluations questions, we also used any other means of evaluation available to us. The evaluate cycle follows the generate cycle.

To use the micro-IS framework, we suggested the constructs, models, and methods to be added, removed, or adapted. We suggest the use of a minimalistic approach: new artifacts should be added to the micro-IS framework only if they are essential to solve a given problem.

\section{Prototypes}

\subsection{Prototype 1 - Proof of Concept}

The first prototype was a "proof of concept" prototype. It was a simple text-output prototype that served to show that it was meaningful and technically possible to make an interactive sensor-intensive prototype to conduct climate management (Figure 4). The prototype was evaluated by internal discussion in the research group using the generate/evaluate tool, Figure 2 and Figure 3, with the aim of conducting a rigorous evaluation. We decided to go on with the LEGO due to its ability to connect to the minds of many people with little technical knowledge and its flexibility in programming capacity, both of which had previously been demonstrated [8, 9].

Lego Mindstorms NXT is the unit that we used to model the sensors and the actuators (motors). The unit has four input sensors, which are in the standard kit: touch (shown in Figure 5), light, sound, and a distance sensor.

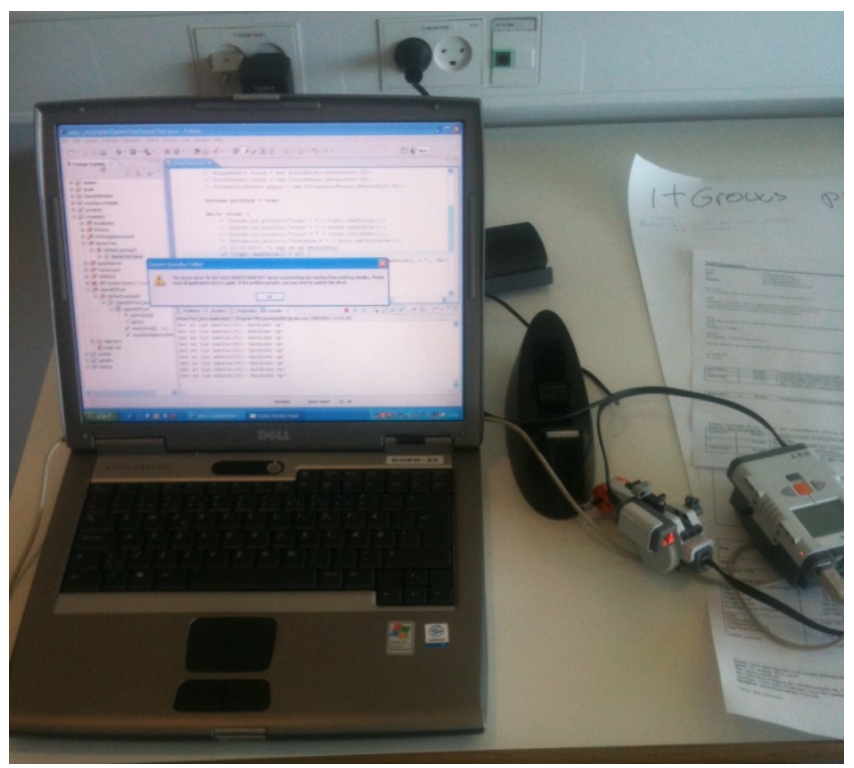

Fig. 4. IT Grows prototype 1 - demonstrating sensor-based climate management prototyping with Lego Mindstorms 


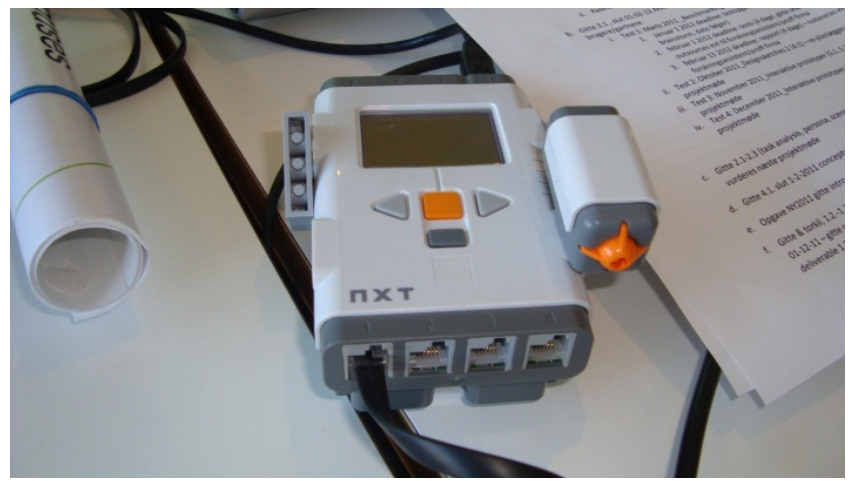

Fig. 5. LegoMindstorms NXT as the platform for prototyping

\subsection{Prototype 2 - Exhibition Demo Prototype}

We used the standard Lego Mindstorm educational kit to prototype an interactive climate management system in a greenhouse (Figure 6). The model greenhouse has one motor that imitates a motor controlling a roof window. When the light sensor values raise above a pre-defined trigger point, the motor opens the window. The opposite event takes place when the monitored light drops below a pre-defined set point: the window closes. A wind speed sensor is mounted on the top of the roof, but, similar to other imaginable relevant sensors, this was not connected to the climate computer (the Lego Mindstorms NXT) in this prototype version.

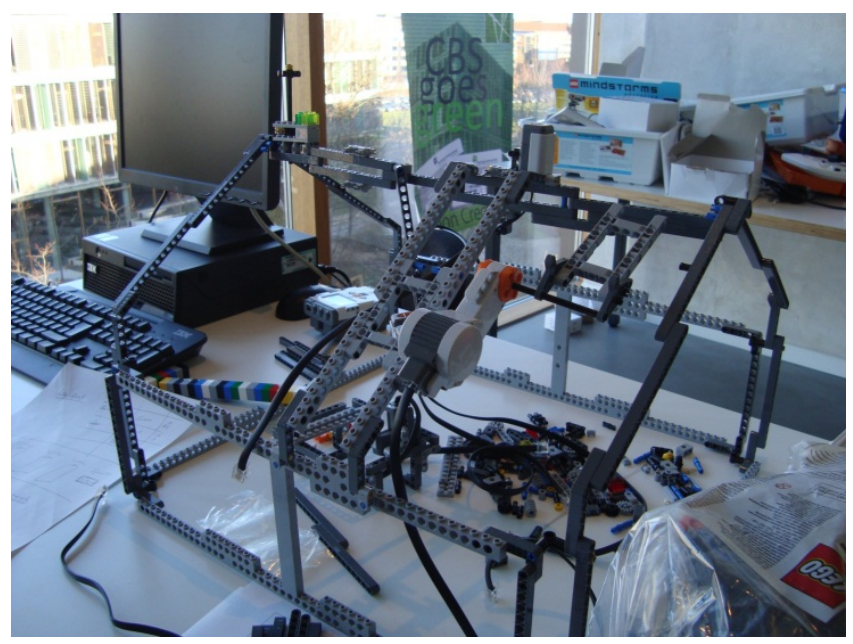

Fig. 6. Prototype 2 - Model of greenhouse

Prototype 2, shown in Figure 6, was made to demonstrate that the prototype was easy to disassemble and reassemble in new contexts and that it would allow different users and other stakeholder groups to interact with the prototype. Prototype 2 was 
exhibited at two major international exhibitions for commercial climate management systems (Figure 7). The evaluation was done by the first author via an email interview with the senior project leader in the company who had taken the prototypes to the exhibitions. Somewhat against expectations, the project leader reported that the prototype was never made to run in the sense of having the LEGO Mindstorm computer operating, but she said that it nevertheless generated plenty of interest from conference participants, who easily could imagine interacting with the demo climate management system.

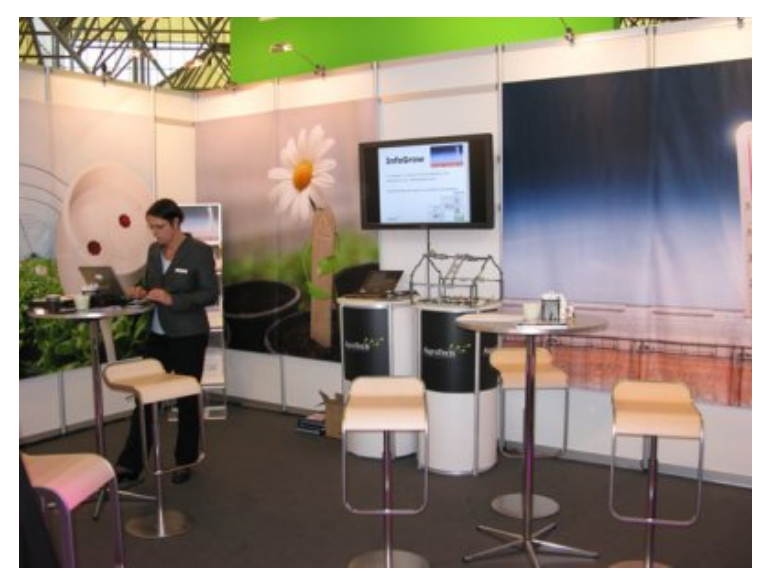

Fig. 7. Lego greenhouse climate management prototype displayed at greenhouse grower exhibition.

\subsection{Prototype 3 - Functionally Working Climate Control}

The third prototype was aimed at generating relevant functions that would allow greenhouse growers to interact with real sensor data. A single temperature sensor was installed on top of a simulated standard greenhouse table with potted plants, Figure 8. The evaluation was done by the first author in the role of expert programmer. It revealed the need for programming specific object classes for the temperature sensor in order to calculate the level of photosynthesis and generate data that the greenhouse growers would be able to evaluate. We also found that the model table (see Figure 8) was not sufficient. It needed to be larger and to hold biological plant material.

\subsection{Prototype 4 - Interacting with a Climate Consultant}

The fourth prototype was made in order to interact with a greenhouse grower consultant. He examined the prototype and suggested a number of uses and improvements. He showed real engagement in terms of its use. The evaluation was done by a group discussion between the authors and the consultant. One point was that the prototype should be taken seriously as a potential way to generate innovations in reference to 


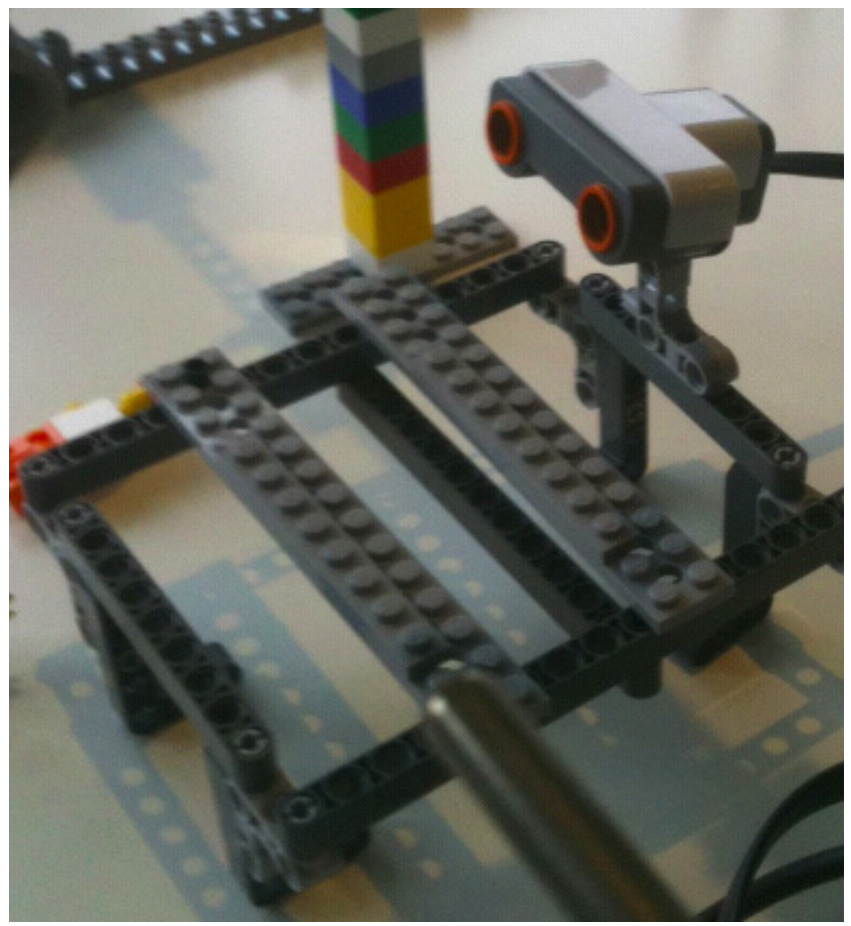

Fig. 8. Prototype 3 - The simulated plant table that should hold plant material for obtaining real sensor data

climate control. For example, the prototype generated group discussions and shared sketches about how exactly to locate and use multiple sensors inside and outside real greenhouses (Figure 9). Secondly, the need for going beyond simple data logging and moving toward more advanced data visualization when supporting interactions with climate management specialists became evident.

\subsection{Prototype 5 - Showing Relative Data from Many Sensors}

Prototype 5 was developed with the purpose of simulating the more realistic scenario of managing several sensors from several greenhouses. Additional Lego blocks were needed. In addition, we attempted to add plastic to simulate the climate screen (This did not go so well) and we installed more sensors. A new programming environment (Lejos) replaced the LEGO Mindstorm software. The evaluation focused on the "realness" of the data; again, a greenhouse consultant interacted with the prototype.

The use of "real" electronic components at this point in the prototyping process was introduced to experiment with the sensitivity and usefulness of sensors. For each new component, it was necessary to first (1) go through the work of finding an (electronic) component and then to start the actual process measurements, confirming that they worked, and calibrating each sensor. With respect to a light sensor for an example of the process, see Figure 10, Figure 11, and Figure 12. 


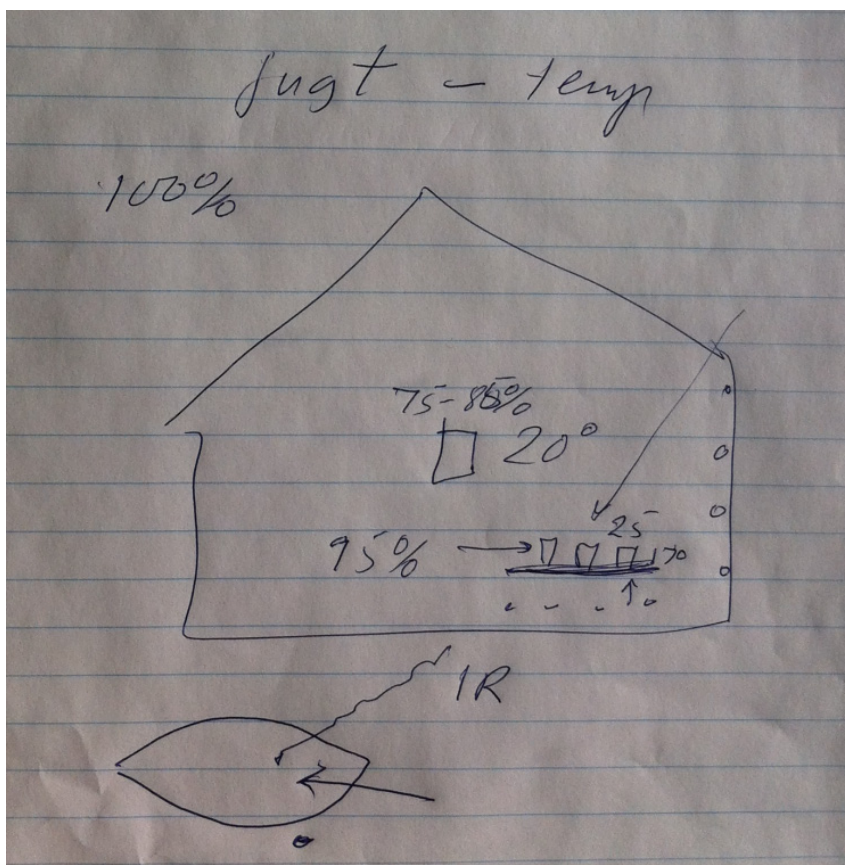

Fig. 9. Group discussion sketch of simulated greenhouse prototype 4

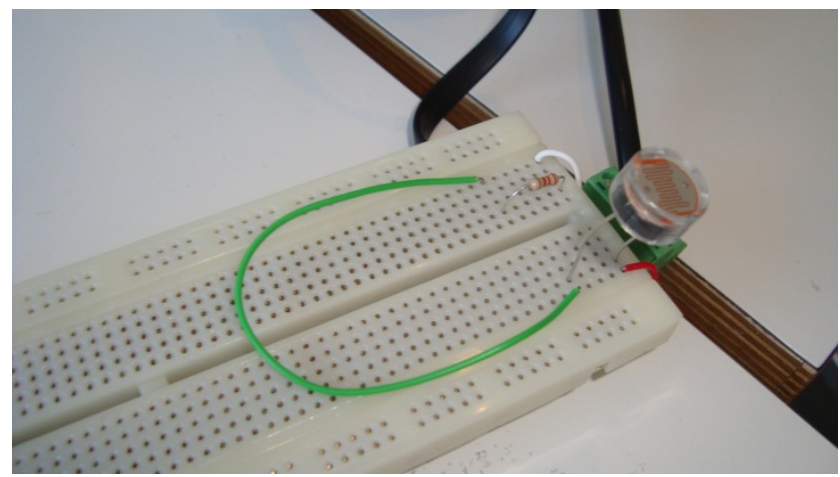

Fig. 10. Prototype 5. An electronic "breadboard" with a light-sensitive resistor

Figure 12 illustrates the Lejos development environment and how the Java code was used to read periodic readings from Lego Mindstorms NXT. For example, a temperature-dependent resistor was used to measure the temperature in the green model greenhouse. Before this was used, we experienced one minor setback with respect to this temperature sensor: it was not directly possible to find a way to interface Lejos with this sensor. A secondary potential challenge was that the original Lego temperature sensor was becoming an added expense since the micro-climate controller in further prototyping should be using several temperature measurements. 


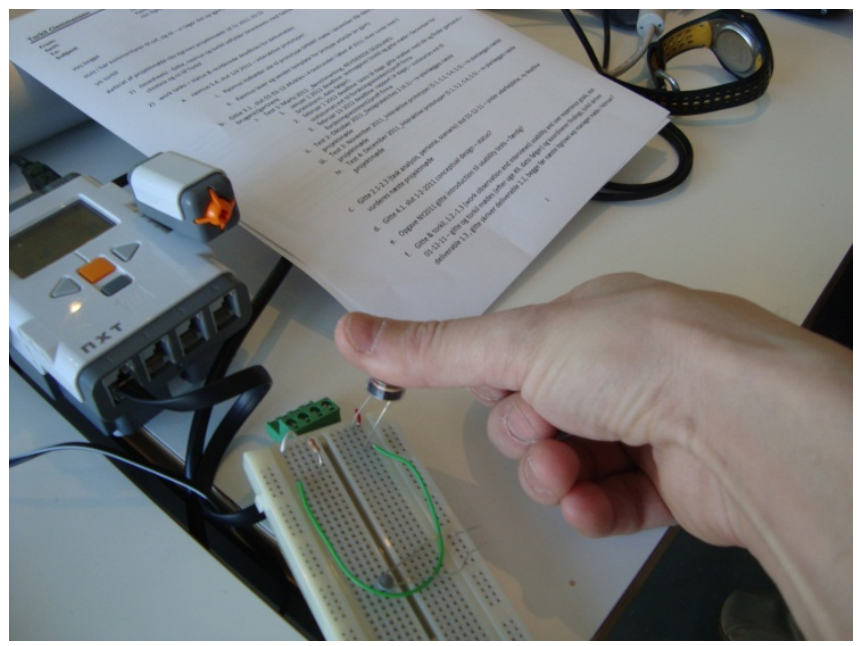

Fig. 11. Testing and calibrating the light sensor

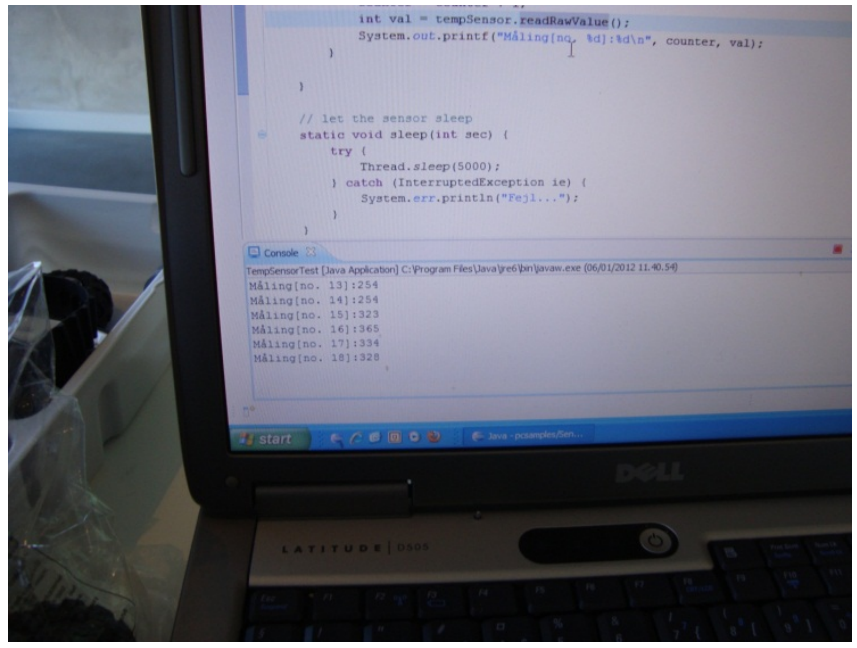

Fig. 12. Testing connectivity to a laptop

\subsection{Prototype 6 - Students' Cognitive Walkthrough of a High Fidelity Prototype}

Prototype 6 was a high fidelity prototype of a part of the to-be-designed climate management system, the "side-bar" which gave decision support to the grower based on model simulations of the climate (Figure 13). Three student groups from a second year computer science and business administration study from the second author's course conducted a cognitive walkthrough [26] of the prototype in Figure 13. 


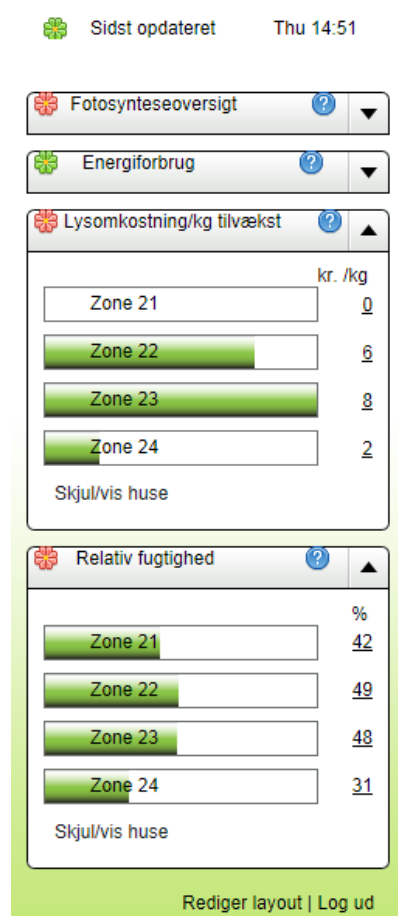

Fig. 13. The current running conceptual prototype of the decision support part of an interactive sensor-intensive climate management system (courtesy of Agrotech)

The results of the cognitive walkthrough were sent to the developers, who stated that some results - that is, some design suggestions in reference to consistency, level of detail, and scalability of graphs were particularly useful in the further development of the system.

\section{Discussion}

We have described the complete development flow of a sensor-intensive prototype within a DSR generate-evaluate process (Figure 2). Table 1 provides an overview. Among the possible points for discussion are:

- The use of LEGO Mindstorm as a sensor-intensive prototyping tool is, we believe, the first attempt to make "throw-away" sensor-intensive prototypes. It is easy to assemble, disassemble, move, and re-assemble; in that way, we were able to reproduce the different LEGO Mindstorm sensor-intensive prototypes. Hence the evaluation results can potentially be repeated and easily reproduced by other researchers.

- The "throw-away" nature of the prototypes, that is, the easy reproducibility of the sensor-intensive prototypes, may, among other considerations, provide a solution to the problem raised in related HCI research: How to allow HCI designers to develop a necessary level of understanding to design relatively simple user interfaces 
for complex work domains [27], such as the horticultural domain, and, in particular, how to do this within a reasonable time period [20].

Climate management and climate control overlap in our proposed combination of micro-IS and HCI approaches to greenhouse climate. Thus, we accommodated the proposals [18] to allow growers to use a two-system approach.

In operational climate management, the actions taken by the one(s) using the systems are dependent upon timely readings of temperature, humidity, light intensity, etc. Lego Mindstorms provides these readings and, thus, it provides the dynamic picture which is a requirement of such systems. Furthermore, Lego Mindstorms can control the greenhouse prototypes with its motors. We have used the motors to simulate the opening and closing of curtains.

Combining Micro-IS with HCI research can be done by using design science and the related process for this research as an overall framework.

\subsection{Research Contributions}

We have demonstrated the usefulness of using a design science research framework to combine Micro-IS with HCI research. We have used the Micro-IS/HCI approach in the development of six interactive sensor-intensive throw-away prototypes. A special valuable property of our approach is that we are explicit about the roles that are

Table 1. Generation of prototypes and their evaluation in growers' work domains and interaction design evaluation

\begin{tabular}{|c|c|c|c|}
\hline \multirow{7}{*}{$\begin{array}{c}\mathbf{T} \\
\mathbf{I} \\
\mathbf{M} \\
\mathbf{E}\end{array}$} & $\begin{array}{c}\text { Work domain and task } \\
\text { evaluation }\end{array}$ & $\begin{array}{c}\text { Generation of } \\
\text { prototypes }\end{array}$ & $\begin{array}{c}\text { Interaction design eval- } \\
\text { uation }\end{array}$ \\
\hline & Field test in greenhouse & $\begin{array}{l}\text { Prototype } 6 \text { - Decision } \\
\text { support part of system }\end{array}$ & $\begin{array}{l}\text { Cognitive walk-through } \\
\text { by students of HCI }\end{array}$ \\
\hline & $\begin{array}{l}\text { Review by expert in } \\
\text { sensor information }\end{array}$ & $\begin{array}{l}\text { Prototype } 5 \text { - Light } \\
\text { sensitive resistor }\end{array}$ & - \\
\hline & - & $\begin{array}{c}\text { Prototype } 4 \text {-Sketches of } \\
\text { model greenhouse simula- } \\
\text { tion }\end{array}$ & $\begin{array}{l}\text { Evaluation of sketches by } \\
\text { greenhouse consultant }\end{array}$ \\
\hline & $\begin{array}{c}\text { Group discussion with } \\
\text { greenhouse grower } \\
\text { consultant }\end{array}$ & $\begin{array}{c}\text { Prototype } 3 \text {-Simulated } \\
\text { plant table }\end{array}$ & - \\
\hline & $\begin{array}{l}\text { Presentation of LEGO } \\
\text { greenhouse climate } \\
\text { management for indus- } \\
\text { try }\end{array}$ & $\begin{array}{c}\text { Prototype } 2 \text { - Model of } \\
\text { greenhouse }\end{array}$ & - \\
\hline & $\begin{array}{c}\text { Within project team, } \\
\text { evaluation of sensordata } \\
\text { collection by generate/ } \\
\text { evaluate tool }\end{array}$ & $\begin{array}{l}\text { Prototype } 1 \text { - LEGO } \\
\text { Mindstorm unit }\end{array}$ & $\begin{array}{l}\text { Within project team, } \\
\text { evaluation of interaction } \\
\text { design by gener- } \\
\text { ate/evaluate tool }\end{array}$ \\
\hline
\end{tabular}


assumed by each type of generate/evaluate activity throughout the process. This allows for the creation of a lightweight log book of how a project develops over time and the possibility of going back in time to restart the design at a given point.

The design science research in IS has provided us with the established research from which we have focused on the generation of prototypes and the subsequent evaluation of same. We have noted who conducted the creation and evaluation at each point in time. Our generate/evaluate tool is an Eclipse plug-in, which can be provided upon request. This tool was easy to use and served to visualize the process of capturing the generation and evaluation, activities in addition to our videotaping of same.

Sensor-intensive prototyping involves electric engineering and computer science in addition to HCI and end user involvement. We believe that this type of development is different from traditional computer interaction, partly because of the dynamics of the sensor-intensive user interaction compared to a traditional series of screens. With the label "interactive, sensor-intensive prototypes," we want to provide a method that can be used to facilitate collaboration across multiple disciplines.

\section{Conclusion}

The application of a design science framework for combining micro information systems with human-computer interaction approaches adds structure to the design process. In terms of the rigor and relevance research questions that we raised in the beginning of the paper, we have achieved more than we expected.

By adhering to a lightweight process that concentrated on the generate/evaluate process, we were able to undertake a series of prototyping efforts over a period of 18 months and keep track of the progress. The relevance of the "interactive, sensorintensive prototyping" approach has been confirmed by the exhibition of one prototype at a large agriculture exhibition. The rigor has been described in terms of design science, micro information systems, and the ability to reproduce sensor-intensive prototypes.

Acknowledgments. This research was supported by a grant from The Danish National Advanced Technology Foundation (Højteknologifonden) to the itGrows-project.

\section{References}

1. Watson, R.T., Boudreau, M.C., Chen, A.J.: Information systems and environmentally sustainable development: energy informatics and new directions for the IS community. MIS Quarterly 34(1), 23 (2010)

2. Liapis, C., Chatterjee, S.: On a NeuroIS Design Science Model. In: Jain, H., Sinha, A.P., Vitharana, P. (eds.) DESRIST 2011. LNCS, vol. 6629, pp. 440-451. Springer, Heidelberg (2011)

3. Hevner, A.R., March, S.T., Park, J., Ram, S.: Design science in information systems research. MIS Quarterly 28(1), 75-105 (2004) 
4. Adikari, S., McDonald, C., Collings, P.A.: Design Science Approach to an HCI Research Project. In: Proc. OZCHI 2006, pp. 429-432. ACM Press (2006)

5. Carroll, J.M.: Creating a design science of human-computer interaction. Interacting with Computers 5(1), 3-12 (1993)

6. Guinard, D., Trifa, V., Mattern, F., Wilde, E.: From the Internet of Things to the Web of Things: Resource Oriented Architecture and Best Practices. In: Architecting the Internet of Things, ch. 5. Springer (2011)

7. OECD, Smart Sensor Networks: Technologies and Applications for Green Growth. OECD Digital Economy Papers (2009)

8. Pedersen, R.U.: Tinyos education with Lego Mindstorms NXT. In: Learning from Data Streams. Processing Techniques in Sensor Networks, pp. 231-241 (2007)

9. Pedersen, R.U., Nørbjerg, J., Scholz, M.P.: Embedded Programming Education with Lego Mindstorms NXT using Java (leJOS), Eclipse (XPairtise), and Python (PyMite). In: Proceedings of Workshop on Embedded Systems Education, WESW. ACM (2009)

10. Pedersen, R.U., Pedersen, M.K.: Micro Information Systems: New Fractals in an Evolving IS Landscape. In: Integrated Information and Computing Systems for Natural, Spatial, and Social Sciences. IDG Global (2012)

11. Sprague Jr., R.H.: A framework for the development of decision support systems. MIS Quarterly, 1-26 (1980)

12. Pottie, G., Kaiser, W.: Principles of Embedded Networked Systems Design. Cambridge University Press, New York (2005)

13. March, S.T., Storey, V.C.: Design science in the information systems discipline: An introduction to the special issue on design science research. MIS Quarterly 32(4), 725-730 (2008)

14. Pries-Heje, J., Baskerville, R.: The design theory nexus. MIS Quarterly 32(4), 731-755 (2008)

15. Sein, M.K., Henfridsson, O., Purao, S., Rossi, M., Lindgren, R.: Action design research. MIS Quarterly 35(1), 37-56 (2011)

16. Carroll, J.M.: Conceptualizing a possible discipline of human-computer interaction. Interacting with Computers 22(1), 3-12 (2010)

17. Clemmensen, T., Ulslev Pedersen, R.A.: Human Work Interaction Design (HWID) Perspective on Internet - and Sensor Based ICT Systems for Climate Management. In: Ørngreen, R., Wong, W., Rooney, C., Barnett, J., Hvannberg, E., Clemmensen, T. (eds.) Post-Workshop Proceedings for: Crisis management training, design and use of online worlds, http://pure.au.dk/portal/files/44017637/Crisis_Manageme nt_Training_Post_Workshop_Proceedings.pdf

18. Van Straten, G., Challa, H., Buwalda, F.: Towards user accepted optimal control of greenhouse climate. Computers and Electronics in Agriculture 26(3), 221-238 (2000)

19. Pearce, J., Smith, W., Nansen, B., Murphy, J.: SmartGardenWatering: Experiences of Using a Garden Watering Simulation. In: Proc. of OZCHI 2009, pp. 217-224. ACM Press (2009)

20. Pearce, J., Murphy, J., Smith, W.: Supporting Gardeners to plan Domestic Watering: A Case Study of Designing an "Everyday Simulation". In: Proc. of OZCHI 2008, pp. 227-230. ACM Press (2008)

21. Burns, C.M., Hajdukiewicz, J.R.: Ecological interface design. CRC (2004)

22. Dourish, P.: HCI environmental sustainability: the politics of design and the design of politics. In: Proc. of DIS 2010, pp. 1-10. ACM Press (2010) 
23. Nathan, L., Friedman, B., Hendry, D.: SUSTAINABLY OURS: Information system design as catalyst: Human action and environmental sustainability. Interactions 16(4), 6-11 (2009)

24. Mankoff, J.C., Blevis, E., Borning, A., Friedman, B., Fussell, S.R., Hasbrouck, J., Woodruff, A., Sengers, P.: Environmental sustainability and interaction. In: Ext. Abstracts CHI 2007, pp. 2121-2124. ACM Press (2007)

25. Körner, O., Clemmensen, T., Petersen, R.U., Ottosen, C.-O.: itGrows - Module-based IT Platform for Optimizing Horticultural Production. The Danish National Advanced Technology Foundation (Højteknologifonden) (2010)

26. Mahatody, T., Sagar, M., Kolski, C.: State of the art on the cognitive walkthrough method, its variants and evolutions. Intl. Journal of Human-Computer Interaction 26(8), 741-785 (2010)

27. Clemmensen, T.: Designing a simple folder structure for a complex domain. Human Technology: An interdisciplinary Journal on Humans in ICT 7(3), 216-249 (2011) 